\title{
Magnitude of Episiotomy and Associated Factors among Mothers Who Give Birth in Arba Minch General Hospital, Southern Ethiopia: Observation-Based Cross-Sectional Study
}

\author{
Kassahun Fikadu, ${ }^{1}$ Negussie Boti ${ }^{D},{ }^{2}$ Birtukan Tadesse, ${ }^{1}$ Dureti Mesele, ${ }^{1}$ Emenet Aschenaki, ${ }^{1}$ \\ Etenesh Toka, ${ }^{1}$ Fistum Arega, ${ }^{1}$ Tsehaynesh Girma, ${ }^{1}$ and Abebech Paulos ${ }^{1}$ \\ ${ }^{1}$ Midwifery Department, College of Medicine and Health Sciences, Arba Minch University, Arba Minch, Ethiopia \\ ${ }^{2}$ School of Public Health, College of Medicine and Health Sciences, Arba Minch University, Arba Minch, Ethiopia \\ Correspondence should be addressed to Negussie Boti; kahlidboti@gmail.com
}

Received 12 January 2020; Revised 20 July 2020; Accepted 24 July 2020; Published 1 September 2020

Academic Editor: Marco Scioscia

Copyright (c) 2020 Kassahun Fikadu et al. This is an open access article distributed under the Creative Commons Attribution License, which permits unrestricted use, distribution, and reproduction in any medium, provided the original work is properly cited.

\begin{abstract}
Background. Episiotomy is the most common obstetric procedure, performed when the clinical circumstances place the patient at a high risk of high-degree laceration. However, episiotomy should be done with judicious indication to lower perineal laceration with fewer complications. Despite its adverse effects, the magnitude of episiotomy is increasing due to different factors. Therefore, this study is aimed at determining the recent magnitude of episiotomy and at identifying associated factors among women who gave delivery in Arba Minch General Hospital, Southern Ethiopia. Methods. An institution-based cross-sectional study was conducted from December 15, 2018, to January 30, 2019. A systematic random sampling technique was used to select study participants. A semistructured questionnaire was used to collect data. This was supplemented with a review of the labor and delivery records. Binary and multivariable logistic regression analyses were performed to identify factors associated with the magnitude of episiotomy. $P$ value $\leq 0.05$ was used to determine the level of statistically significant variables. Results. The magnitude of episiotomy was found to be $272(68.0 \%)$ with $95 \% \mathrm{CI}=64.0-72.5$. Women who attended secondary education $[\mathrm{AOR}=10.24,95 \% \mathrm{CI}=2.81-37.34]$, women who attended college and above $[\mathrm{AOR}=4.61,95 \% \mathrm{CI}=1.27-16.71]$, birth weight $\geq$ $3000 \mathrm{~g}[\mathrm{AOR}=4.84,95 \% \mathrm{CI}=2.66-8.82]$, primipara $[\mathrm{AOR}=4.13,95 \% \mathrm{CI}=2.40-7.12]$, being housewife occupants $[\mathrm{AOR}=3.43$, $95 \% \mathrm{CI}=1.20-9.98]$, married women $[\mathrm{AOR}=2.86,95 \% \mathrm{CI}=1.40-5.84]$, and body mass index $<25 \mathrm{~kg} / \mathrm{m}^{2}[\mathrm{AOR}=2.85,95 \% \mathrm{CI}=$ 1.50-5.44] were independent variables found to have significant association with episiotomy. Conclusion. The magnitude of episiotomy was $68.0 \%$ which is higher than the recommended practice by WHO (10\%). The study participants' occupational status, marital status, educational status, parity, birth weight, and BMI were significantly associated with the magnitude of episiotomy in the study area. Therefore, to reduce the rate of episiotomy, it is better to have periodic training for birth attendants regarding the indication of episiotomy.
\end{abstract}

\section{Background}

An episiotomy is one of the widely used obstetric interventions which is done by the birth attendant to minimize the risk of severe tears which occur due to enlarging of the birth canal during childbirth at a time when the fetus's head descends $[1,2]$.

The American College of Obstetricians and Gynecologists (ACOG) and Federation of International Gynecology and Obstetricians recommend that episiotomy should be done with judicious indication to lower perineal laceration with fewer complications $[3,4]$. Existing evidence also supported the recommendation to restrict episiotomy use [5].

The finding from studies conducted in a different part of the world shows that episiotomy increases the risk of thirdand fourth-degree perineal lacerations which had short- and long-term complications for mothers [6-8]. A study conducted in Taiwan indicated that episiotomy increased the 
number of women who had pain at the first, second, and sixth weeks of postpartum and urinary incontinence [9]. Most of the consequences of episiotomy affect the parturient, greatly impacting her quality of life and leaving her with an unpleasant childbirth memory [10]. Besides, the findings show that the perineal tear and pelvic floor morbidity can be increased among women receiving episiotomy $[11,12]$. Episiotomy use is associated with a higher incidence of perineal pain in the immediate postpartum period, where it predisposes them to risk of psychological morbidity and stress urinary incontinence in 6 weeks postpartum.

Despite its adverse effects, the magnitude of the episiotomy is increasing due to different factors [13]. Findings from studies conducted in India and China show that the magnitude of episiotomy continues to be high which range from $60 \%$ to $80 \%$ [13-15]. It also continues to be high in developing countries $[1,16,17]$.

The finding from studies conducted in different parts of Ethiopia revealed that the magnitude of episiotomy became over $30 \%$ and the practice was reported to increase up to 2.3 -folds more in a rural part of Ethiopia $[15,17]$. The rate of episiotomy practice reported was significantly higher than recommended, noting that perineal repair without analgesia needs to be revised and a less painful method should be advocated [18]. Moreover, a national health facility report in Ethiopia indicated that episiotomy alone had caused $9 \%$ and $8 \%$ of primary postpartum hemorrhage and maternal sepsis, respectively [19].

The magnitude of episiotomy practice varies according to the obstetric procedure, maternal and fetal conditions, type of birth attendant, level of education, and years of experience of birth attendant. Therefore, this study is aimed at determining the recent magnitude of episiotomy and at identifying associated factors among women who gave delivery in Arba Minch General Hospital, Gamo Zone, southern Ethiopia, which may help to reduce adverse consequences to the mother. Moreover, the finding of this study may help clinicians to make an informed decision about episiotomy-related clinical practice, thereby achieving the best pregnancy outcome.

\section{Methods}

2.1. Study Area, Period, and Design. An institution-based, cross-sectional study was conducted from December 15, 2018, to January 30, 2019, in Arba Minch General Hospital. Arba Minch is an administrative town of the Gamo Zone, located about approximately $500 \mathrm{~km}$ south of Addis Ababa, the country's capital city. It consists of 11 Kebele (the smallest administrative unit) with a total population of 112,724 . There are 26,265 reproductive age group [14] women residing in the town of whom 4428 were pregnant and 3261 were giving birth at the facility level. There is one general hospital, two health centers, and 17 primary and 14 medium private clinics in the town. Arba Minch Hospital is teaching center in different disciplines and specialty areas for medicine and health science students ..

2.2. Source and Study Population. Those mothers who gave birth in Arba Minch General Hospital during the specified study period were eligible for the study. However, mothers who underwent destructive delivery were excluded from this study.

2.3. Sample Size Determination and Sampling Procedure. The sample size was estimated using a single population proportion formula considering the following assumptions: the magnitude of episiotomy ( $P=41.4 \%)$ from the study conducted in public health institutions of Axum Town, Northern Ethiopia [20]; confidence level of 95\%; 5\% of the margin of error; and $10 \%$ nonresponse rate. As a result, the calculated sample size for this study was 410 . To select study participants, the systematic random sampling technique was employed. The sampling process was stopped when the required sample size was met. The sampling interval was determined based on the monthly average number of deliveries. Accordingly, the hospital report in the year 2018 of the average monthly number of deliveries was 1315 (i.e., $K^{\text {th }}$ value $1315 / 410=3.2 \sim 3$ ). The initial mother was picked by lottery method, then the next mother was selected every three intervals according to their order of admission to labor until the final sample size was fulfilled.

2.4. Data Collection Method. Data was collected using a pretested, interviewer-administered, semistructured questionnaire. This tool was developed from similar studies conducted in a different part of the world [17, 20-27]. The questionnaire was primarily developed in English, translated into Amharic (local language), then translated back to English and rechecked by the third person, to ensure its correctness and consistency. The interview questionnaire consisted of four key items: sociodemographic characteristics of participants, labor- and delivery-related factors, and maternal- and fetal-related variables. Fetal gestation and weight were collected from the maternal follow-up sheet.

Seven BSc midwives who had experience in data collection were selected for data collection and three MSC midwifery students supervised the data collection. All data collectors were responsible for observing respondents starting from the commencement of the active first stage of labor to the occurrence of the outcome. Then, the secondary data extraction follows until the patient has had a stable vital sign and her medical condition has been confirmed for interview by a duty physician. Then, the interview was conducted in a place where the mother's privacy and comfort could be kept. All interviews were conducted in the local language. The data collectors were supervised by MSC midwifery students based on hospital ward rotation. The data collectors were scheduled in every shift to collect data from the admission of parturient to the end of the first two hours after childbirth through an interview, observation, and delivery records. The data collectors used a unique numeric identifier to track the mothers' card back during data extraction. They were instructed to put this code on each questionnaire's front page. Each time during the data collection phase, between 5:00 and 5: $30 \mathrm{pm}$, we had a regular meeting to discuss challenges. Then, the research was notified right away to make a solution for the next day. The interviews ranged from 10 to 15 min per participant. All study subjects were permitted to be interviewed. 
2.5. Data Quality Management. To control data quality, the questionnaire was pretested in $5 \%$ of the sample size among women who gave birth in Gidole Hospital. A minor amendment on consistency, coherence, and skipping patterns was made after a pretest was conducted. Besides, both the data collectors and supervisor had been given one-day training on how to complete questionnaires, interview puerperal patients, and extract data from the delivery registration by the researcher. During the data collection phase, the supervisor checked the completeness of the questionnaire each day.

2.6. Data Analysis. The collected data were coded, entered, and cleaned by using Epi Info version 7.2.0 software. Then, it was exported to SPSS version 20. Descriptive statistics were carried out and summarized by tables, frequencies, graphs, and means. An association between the magnitude of episiotomy and potential factors was examined using binary logistic regression. The odds ratio and confidence interval were calculated to determine the strength of the association. From the bivariable analysis, those variables $P \leq 0.25$ and biological plausibility were potential candidates for multivariable logistic regression analysis. We check multicollinearity between variables and outcome variables by using a variance inflation factor (VIF). Variables with a VIF greater than 10 were dropped from the candidate variables to be fitted into the final model. The goodness-of-fit was assessed using the Hosmer-Lemeshow test. Variables with a nonsignificant Pearson chi-square test but a significant omnibus test were considered eligible to be fitted to the multivariable model. Variables with a $P$ value $\leq 0.05$ in the multivariable logistic regression model were considered statistically significant. Finally, the significance of an association between episiotomy received and independent variables was reported with corresponding 95\% CI.

\section{Results}

3.1. Sociodemographic Characteristics of the Study Subjects. Out of 410 mothers who were expected to participate, 400 mothers participated in this study, which gave a $97.6 \%$ response rate. The majority of $193(48.3 \%)$ of the study subjects were less than 27 years of age with a 3.9 standard deviation. Of all study subjects, more than $85 \%$ were married. Most of the 255 (63.8\%) study subjects in this study lived in an urban area. More than $29 \%$ of the study subjects were either government or self-employees. About $26.8 \%$ of the study participants had completed at least a college education (Table 1).

3.2. Labor- and Delivery-Related Characteristics. In this study, about $207(51.8 \%)$ respondents had given birth during the night time. More than $39 \%$ of the respondents had given birth assisted by a vacuum extractor. Regarding duration of labor, 224 (56\%) laboring mothers stayed more than 7 hours in the first stage of labor. However, 222 (55.5\%) of laboring mothers took less than 2 hours to deliver their neonates after commencement of the second stage. Two hundred and thirty-four, $58.5 \%$, of study subjects had given birth assisted by midwife professionals (Table 2).
TABLE 1: Sociodemographic characteristics of respondents on magnitude and factors of episiotomy in Arba Minch General Hospital, Southern Ethiopia.

\begin{tabular}{lcc}
\hline Variables & Frequency $(n)$ & Percentage $(\%)$ \\
\hline Age classification & & \\
$\quad<27$ years & 262 & 65.50 \\
$\geq 27$ years & 138 & 34.50 \\
\hline Marital status & & \\
$\quad$ Unmarried & 57 & 14.20 \\
Married & 343 & 85.80 \\
\hline Resident & & \\
Urban & 255 & 63.80 \\
Rural & 145 & 36.20 \\
\hline Occupation & & \\
Housewife & 97 & 24.30 \\
Employee & 117 & 29.30 \\
Merchant & 104 & 26.00 \\
Student & 82 & 20.40 \\
\hline Educational states & & \\
Nonformal education & 97 & 24.30 \\
Primary & 99 & 24.80 \\
Secondary & 97 & \\
Collage and above & 107 & \\
\hline
\end{tabular}

3.3. Maternal-Related Characteristics. Of the total multiparous women in this study, 91 (48.4\%) of them had a history of previous episiotomy being performed. Among mothers who had pregnancy above 28 completed weeks, 60 (31.9\%) of them had a history of previous breech delivery. Among the total respondents, the majority, 325 (81.3\%) respondents, had female genital mutilation. About 212 (56\%) of the respondents had given birth for the first time. Approximately fifty-two percent of the respondents were found to have a body mass index of more than the optimal range. In 103 (25.8\%) mothers, a previous history of chronic illness was reported (Table 3).

3.4. Fetal-Related Characteristics. Out of the total delivery, 298 (74.5\%) were born at the beginning of 37 and above completed weeks of gestation. The majority of 363 (90.8\%) of the reported fetal presentation was cephalic. During the current study, the fetal condition was described by the presence of clear amniotic fluid in 308 (77\%) of the respondents. More than half of the delivered neonates had less than $3300 \mathrm{gm}$ $(\mathrm{IQR} \pm 2000)$ (Table 4).

3.5. Magnitude of Episiotomy. The findings of this study revealed that the magnitude of episiotomy was found to be $272(68.0 \%)$ with $95 \% \mathrm{CI}=64.0-72.5$. In this study, the main reason for performing episiotomy procedure was fear of spontaneous perinatal laceration, accounting for $55.8 \%$, followed by $15.8 \%$ where it was rated for soft tissue dystocia (Figure 1). 
TABLE 2: Labor- and delivery-related characteristics of the study on magnitude and associated factors of episiotomy in Arba Minch General Hospital, Southern Ethiopia, 2019.

\begin{tabular}{lcc}
\hline Variables & Frequency $(n)$ & Percentage (\%) \\
\hline A shift of delivery completion & & \\
$\quad$ Night & 207 & 51.80 \\
$\quad$ Day & 193 & 48.20 \\
\hline Vacuum extractor application & & \\
$\quad$ Yes & 153 & 39.20 \\
$\quad$ No & 247 & 61.80 \\
\hline Duration of first-stage labor & & \\
$\quad$ Less than 7 hours & 176 & 44.00 \\
$\quad$ Greater or equal to 7 hours & 224 & 56.00 \\
\hline Duration of second-stage labor & & \\
$\quad \leq 2$ hours & 222 & 55.50 \\
$\quad>2$ hours & 178 & 45.50 \\
\hline Birth attendant & & \\
$\quad$ Midwife & 234 & 58.50 \\
$\quad$ Other health care provider & 166 & 41.50 \\
\hline
\end{tabular}

TABLE 3: Maternal-related characteristics of the study on magnitude and associated factors of episiotomy in Arba Minch General Hospital, Southern Ethiopia, 2019.

\begin{tabular}{lcc}
\hline Variables & Frequency $(n)$ & Percentage (\%) \\
\hline Previous episiotomy $(n=188)$ & & \\
$\quad$ Yes & 91 & 48.40 \\
No & 97 & 51.60 \\
\hline Previous breech delivery $(n=188)$ & & \\
$\quad$ Yes & 60 & 31.90 \\
$\quad$ No & 128 & 68.10 \\
\hline Female genital mutilation & & \\
$\quad$ Yes & 325 & 81.30 \\
$\quad$ No & 75 & 18.70 \\
\hline Parity & & \\
Primipara & 212 & 53.00 \\
Multipara & 188 & 47.00 \\
\hline Body mass index & & \\
$<25 \mathrm{~kg} / \mathrm{m}^{2}$ & 193 & 48.30 \\
$\geq 25 \mathrm{~kg} / \mathrm{m}^{2}$ & 208 & 51.80 \\
\hline History of chronic illness & & \\
Yes & 103 & 25.80 \\
No & 297 & 74.30 \\
\hline
\end{tabular}

3.6. Factors Associated with the Magnitude of Episiotomy. From the bivariable analysis, those variables $P \leq 0.25$ and biological plausibility were potential candidates for multivariable logistic regression analysis. Variables like marital status, maternal age, parity, educational status, occupation, birth
TABLE 4: Fetal-related characteristics of the study on magnitude and associated factors of episiotomy in Arba Minch General Hospital, Southern Ethiopia, 2019.

\begin{tabular}{lcc}
\hline Variables & Frequency $(n)$ & Percentage (\%) \\
\hline Gestational age & & \\
$\quad$ Preterm & 102 & 25.50 \\
Term and above & 298 & 74.50 \\
\hline Fetal presentation & & \\
$\quad$ Cephalic & 363 & 90.80 \\
$\quad$ Breech & 37 & 9.20 \\
\hline Liquor status & & \\
Clear & 308 & 77.00 \\
Bloody & 60 & 15.00 \\
Meconium & 32 & 8.00 \\
\hline Fetal weight & & \\
$<3300$ gm & 175 & 53.80 \\
$\quad \geq 3300$ gm & 225 & 56.20 \\
\hline
\end{tabular}

attendant, duration of second-stage labor, residence, gestational age, time of delivery, history of FGM, estimated fetal weight, history of chronic illness, and body mass index were fitted in the final multivariable model. Those variables like occupation, BMI, birth weight, parity, marital status, and educational status were significantly associated with the outcome variable in the final multivariable analysis.

In this study, those women who were housewife occupants were found to have a significant statistical association, where being a housewife occupant was more than 3.4 times more likely to get incised during delivery than student mothers $[\mathrm{AOR}=3.4,95 \% \mathrm{CI}=1.2-9.9]$. Mothers who had married were 2.9 times more likely to be incised during delivery than those mothers who were unmarried $[\mathrm{AOR}=2.9$, $95 \% \mathrm{CI}=1.4-5.9]$. Mothers' educational status was another independent variable which found to have a statistically significant association with increased magnitude of episiotomy performance. Mothers who attended secondary education $[\mathrm{AOR}=10.2,95 \% \mathrm{CI}=2.8-37.3]$ and those mothers who attended college and above $[\mathrm{AOR}=4.6,95 \% \mathrm{CI}=1.3-16.7]$ were compared to those mothers who did not attend formal education.

On the other hand, mothers who were primiparous were four times more likely to incur episiotomy procedures than those who were multiparous $[\mathrm{AOR}=4.1,95 \% \mathrm{CI}=2.4-7.1]$. Mothers who gave birth to a neonate whose weight was more than or equal to 3300 gm were 4.8 times more likely to incur an episiotomy procedure during delivery than those of newborns whose weight was below $3300 \mathrm{gm}$ [AOR $=4.8$, $95 \% \mathrm{CI}=2.7-8.8]$. Another explanatory variable that had a significant association with the magnitude of episiotomy in this study was maternal body mass index (BMI). Those mothers whose BMI was $<25 \mathrm{~kg} / \mathrm{m}^{2}$ were nearly three times more likely to incur an episiotomy procedure during delivery than those mothers whose BMI was $\geq 25 \mathrm{~kg} / \mathrm{m}^{2}$ $[\mathrm{AOR}=2.9,95 \% \mathrm{CI}=1.5-5.4)$ (Table 5). 


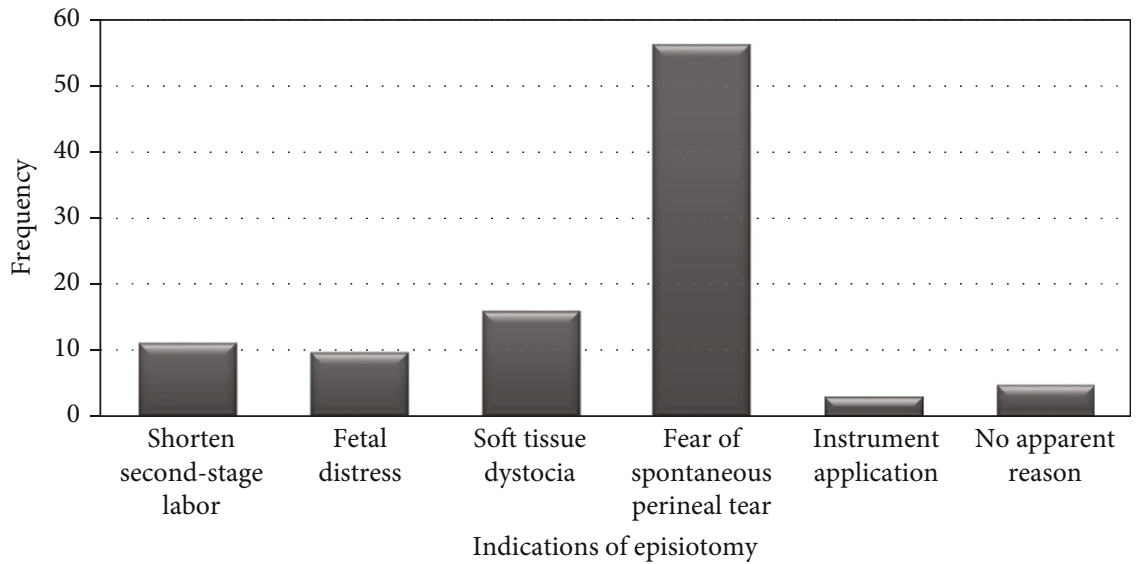

FIGURE 1: Indication of episiotomy among mothers who gave birth in Arba Minch General Hospital, 2019.

TABLE 5: Bivariable and multivariable logistic regression analysis outputs of the factors associated with the magnitude of episiotomy for mothers who gave birth vaginally in Arba Minch General Hospital, $2019(N=400)$.

\begin{tabular}{|c|c|c|c|c|}
\hline \multirow{2}{*}{ Variables } & \multicolumn{2}{|c|}{ Magnitude of episiotomy } & \multirow{2}{*}{ COR $(95 \% \mathrm{CI})$} & \multirow{2}{*}{$\operatorname{AOR}(95 \% \mathrm{CI})$} \\
\hline & Yes & No & & \\
\hline \multicolumn{5}{|l|}{ Occupation status } \\
\hline Housewife & $81(83.5)$ & $16(16.5)$ & $1.9(1.3-4.4)$ & $3.4(1.2-9.9)^{*}$ \\
\hline Employee & $75(64.1)$ & $42(35.9)$ & $0.7(0.8-2.8)$ & $1.5(0.5-4.3)$ \\
\hline Merchant & $56(53.9)$ & $48(46.2)$ & $0.4(0.3-1.1)$ & $1.3(0.5-3.7)$ \\
\hline Students & $60(73.2)$ & $22(26.8)$ & 1 & 1 \\
\hline \multicolumn{5}{|l|}{ Marital status } \\
\hline Unmarried & $26(45.6)$ & $31(54.4)$ & 1 & 1 \\
\hline Married & $246(71.7)$ & $97(28.9)$ & $3.0(1.7-5.4)$ & $2.9(1.4-5.8)^{*}$ \\
\hline \multicolumn{5}{|l|}{ Educational status } \\
\hline No formal education & $52(53.6)$ & $45(46.4)$ & 1 & 1 \\
\hline Primary education & $68(68.7)$ & $31(31.3)$ & $1.9(1.1-3.4)$ & $1.8(0.8-3.9)$ \\
\hline Secondary education & $86(88.7)$ & $11(11.3)$ & $6.8(3.2-14.2)$ & $10.2(2.8-37.3)^{*}$ \\
\hline College and above & $66(61.7)$ & $41(38.3)$ & $1.4(0.8-2.4)$ & $4.6(1.3-16.7)^{*}$ \\
\hline \multicolumn{5}{|l|}{ Parity } \\
\hline Primiparous & $171(80.7)$ & $41(19.3)$ & $3.6(2.3-5.6)$ & $4.1(2.4-7.1)^{*}$ \\
\hline Multiparous & $101(53.7)$ & $87(46.3)$ & 1 & 1 \\
\hline \multicolumn{5}{|l|}{ Birth weight } \\
\hline$<3300$ gm & $83(47.4)$ & $92(52.6)$ & 1 & 1 \\
\hline$\geq 3300 \mathrm{gm}$ & $189(84.0)$ & $36(16.0)$ & $5.8(3.7-9.3)$ & $4.8(2.7-8.8)^{*}$ \\
\hline \multicolumn{5}{|l|}{ Body mass index } \\
\hline$<25 \mathrm{~kg} / \mathrm{m}^{2}$ & $160(83.3)$ & $32(16.7)$ & $4.3(2.7-6.8)$ & $2.9(1.5-5.4)^{*}$ \\
\hline$\geq 25 \mathrm{~kg} / \mathrm{m}^{2}$ & $112(53.9)$ & $96(46.2)$ & 1 & 1 \\
\hline
\end{tabular}

NB: *Significant at $P$ value $\leq 0.05$. COR: crude odds ratio; AOR: adjusted odds ratio; CI: confidence interval; 1: reference group.

\section{Discussion}

The primary objectives of this study were to determine the magnitude of episiotomy and to identify associated factors among women who give birth in Arba Minch General Hospital. As a result, while more than half of women who give birth incurred episiotomy during delivery time, the study partici- pants' occupational status, marital status, educational status, parity, birth weight, and BMI were significantly associated with the magnitude of episiotomy in the study area.

The magnitude of episiotomy was $68.0 \% \quad(95 \% \mathrm{CI}=$ 64.0-72.5). This finding is lower than the study conducted in Uganda (73\%) [28] and in northern Nigeria (89.3\%) [29]. However, this finding is higher than the study conducted in 
Vietnamese-born women in Australia (29.9\%) [27]; Nigeria (21\%) [30]; Brazil 29.1\% [22]; Iran 41.5\% [31]; Kano, Nigeria 41.4\% [32]; Nepal 22\% [33]; East African women in Australia 30\% [34]; Eastern Nigeria 45\% [23]; Mizan Aman 30.6\% [17]; Addis Ababa 40.2\% [16]; Shire 41.4\% [20]; and Jimma 25\% [15]. This difference might be due to the difference in time of the studies conducted, study settings of the study participants, and characteristics of the study population. The high prevalence may be due to the characteristics of the study participant since Arba Minch Hospital was a referral center for three catchment zones. Most women who attend labor in this hospital were high risk and most often referred to with complications; this may increase the risk of episiotomy to shorten the second stage of labor. Another high magnitude of episiotomy might be associated with experiences of birth attendants, which may suggest a more restrictive use at the study center. Also for birth attendants to reduce the episiotomy rate, applicable perineal massage, use of certain birthing positions (e.g., hands and knees), and labor support [35] are suggested. Furthermore, the high magnitude may be associated with operative delivery. In our study, we did not exclude those mothers whose delivery was by vacuum and forced. Evidence shows that operative delivery will increase the rate of episiotomy [36]. Besides, the finding of this study gives a hint on the need for training for professionals in the practice of episiotomy to lower the magnitude of episiotomy.

The finding of this study also revealed that those women whose occupational status was housewives and those women who were married were more likely incised during delivery. This finding is supported by evidence from a study conducted in Mizan Aman Hospital [17].

The educational status of women was also one of the factors with statistically significant associations with an increased magnitude of episiotomy performance. Those women who had attended secondary education and those mothers who attend college and above were more likely incised during delivery compared to those mothers who did not attend formal education. This finding was supported by a study conducted in Iran [31]. This may be due to being educated allows having information or getting aware of the needed interested area. This, in turn, may influence the study subjects to develop a fear towards episiotomy that may influence obstetric caregivers performing episiotomy [37]. This finding also gives a hint for the health profession to apply the WHO recommendation without the influence of mothers.

The parity of respondents was also one of the risk factors for the episiotomy. Those women who were primiparous were more likely to have episiotomy than multiparous women. This finding was supported by studies conducted in Brazil [22], France [8], East African migrants in Australia [34], Taiwan [38], Iran [31], Vietnamese-born women in Australia [27], and Jimma [15]. This might be since most of the time, primiparous women were prone to perineum tightening which is one indication of episiotomy, and the old recommendation of routine episiotomy in primiparous women performed by many health professionals might still have an influence in the indication of this procedure for those women [20].
Birth weight of the newborn had a significant statistical association with episiotomy, where mothers whose newborns had median weight which was equal and more than $3300 \mathrm{mg}$ were 4.8 times more likely to have an episiotomy during parturition. This is in agreement with studies conducted in Israel [39], Nigeria [25], Austria [40], Spain [41], Thailand [42], USA [43], and Japan [44]. However, there was no association reported from a study conducted in Jimma [15] and Iran [31]. This finding gives a hint for clinicians would tend to give episiotomy for a fetus if they assumed the weight was higher. In fact, the higher the estimated fetal weight, the more it could predispose for perinatal trauma if the provider tends to give judicious episiotomy in time. Evidence indicated that one of the main reasons why clinicians used to perform episiotomy was fear of a perineal tear [37]. Training should be given for birth attendants on the indication of episiotomy; this may reduce the fear of the birth attendant. Also, those who fear perineal tear should consult early for an experienced birth attendant.

In the current study, women whose body mass index was less than $25 \mathrm{~kg} / \mathrm{m}^{2}$ were nearly 3 times more likely to have an episiotomy. This is supported by a study conducted in the UK [45], New Mexico [46], and USA [47]. The risk of episiotomy was lower in women who have had an increased BMI [48]. An increased BMI at enrolment was associated with a reduced incidence of minor perinatal trauma at delivery [49]. Obese women were less likely to use tobacco, were more likely to have their labor augmented or induced with oxytocin, and had shorter second stages than women who were not obese [46]. This finding gives a hint for the health professional to follow strictly to those women who were obese.

\section{Limitation of the Study}

As this study was exclusively conducted in the hospital, the findings cannot be generalized to all women who attend labor in Ethiopia. Besides, there may be social desirability bias since we collected the data by using the interviewer administer technique. The cause and effect relationships in this study could not be determined due to the use of the cross-sectional study design for this study. Thus, we strongly recommend further study by using a better study design to ascertain cause relationships.

\section{Conclusion}

In conclusion, this study found that more than half of the study participants have had an episiotomy.

Gravidity, occupational status, marital status, educational status, birth weight of the neonate, and BMI of women were significantly associated with the magnitude of episiotomy. Therefore, different stakeholders working on maternal health programs should work on those factors to reduce the magnitude of episiotomy. Furthermore, it is better to give episiotomy-restrictive interventions to birth attendants. Moreover, clinicians and any responsible body should critically follow the work done in the hospital. 


\section{Abbreviations}

ANC: Antenatal care

AOR: Adjusted odds ratio

BMI: Body mass index

COR: Crude odds ratio

EFW: Estimated fetal weight

WHO: World health organizations.

\section{Data Availability}

The [SPSS/EXCEL] data used to support the findings of this study are available from the corresponding author upon request.

\section{Ethical Approval}

Before the study was conducted, ethical clearance was obtained from the ethical review committee of Arba Minch University, College of Medicine and Health Sciences institutional review board (IRB).

\section{Consent}

Written informed consent was obtained using standard disclosure procedures. Individual identifiers were removed during transcription to maintain the anonymity of information.

\section{Disclosure}

The university has no role in the design of the study; in the collection, analysis, and interpretation of the data; and in writing the manuscript.

\section{Conflicts of Interest}

The authors declare that there is no conflict of interest regarding the publication of this paper.

\section{Authors' Contributions}

All authors contributed equally. They also read and approved the final manuscript.

\section{Acknowledgments}

We would like to acknowledge all study participants for their voluntary participation in this study. We would like to extend our gratitude to Arba Minch University for all the support and opportunity provided to us to conduct this study. Arba Minch University supports this research financially.

\section{References}

[1] J. R. Lappen and D. R. Gossett, "Change in episiotomy practice: evidence based medicine action," Expert Review of Obstetrics \& Gynecology, vol. 5, pp. 301-309, 2014.

[2] A. Jug Došler, A. P. Mivšek, I. Verdenik, T. Škodič Zakšek, T. Levec, and P. Petročnik, "Incidence of episiotomy in Slovenia: the story behind the numbers," Nursing \& Health Sciences, vol. 19, no. 3, pp. 351-357, 2017.
[3] A. H. Nassar, G. H. A. Visser, D. Ayres-de-Campos et al., "FIGO statement: restrictive use rather than routine use of episiotomy," International Journal of Gynaecology and Obstetrics, vol. 146, no. 1, pp. 17-19, 2019.

[4] "The American Congress of Obstetricians and Gynecologists. ACOG Recommends Restricted Use of Episiotomies," 2013, https://www.acog.org/About_ACOG/News_Room/News_ Releases/2006/ACOG_Recommends_Restricted_Use_of_ Episiotomies.

[5] G. Carroli and L. Mignini, "Episiotomy for vaginal birth," Cochrane Database of Systematic Reviews, no. 1, article Cd000081, 2009.

[6] A. Williams, S. Herron-Marx, and H. Carolyn, "The prevalence of enduring postnatal perineal morbidity and its relationship to perineal trauma," Midwifery, vol. 23, no. 4, pp. 392-403, 2007.

[7] M. Macleod, K. Goyder, L. Howarth, R. Bahl, B. Strachan, and D. J. Murphy, "Morbidity experienced by women before and after operative vaginal delivery: prospective cohort study nested within a two-centre randomised controlled trial of restrictive versus routine use of episiotomy," BJOG: An International Journal of Obstetrics \& Gynaecology, vol. 120, no. 8, pp. 1020-1027, 2013.

[8] K. Goueslard, J. Cottenet, A. Roussot, C. Clesse, P. Sagot, and C. Quantin, "How did episiotomy rates change from 2007 to 2014? Population-based study in France," BMC Pregnancy and Childbirth, vol. 18, no. 1, p. 208, 2018.

[9] S.-R. Chang, K. H. Chen, H. H. Lin, Y. M. Y. Chao, and Y. H. Lai, "Comparison of the effects of episiotomy and no episiotomy on pain, urinary incontinence, and sexual function 3 months postpartum: a prospective follow-up study," International Journal of Nursing Studies, vol. 48, no. 4, pp. 409-418, 2011.

[10] P. J. Bex and G. J. Hofmeyr, "Perineal management during childbirth and subsequent dyspareunia," Clinical and Experimental Obstetrics \& Gynecology, vol. 14, no. 2, pp. 97-100, 1987.

[11] L. L. Albers, K. D. Sedler, E. J. Bedrick, D. Teaf, and P. Peralta, "Factors related to genital tract trauma in normal spontaneous vaginal births," Birth, vol. 33, no. 2, pp. 94-100, 2006.

[12] A. Islam, A. Hanif, A. Ehsan, S. Arif, S. K. Niazi, and A. K. Niazi, "Morbidity from episiotomy," The Journal of the Pakistan Medical Association, vol. 63, no. 6, pp. 696-701, 2013.

[13] S. Singh, T. Thakur, N. Chandhiok, and B. S. Dhillon, "Pattern of episiotomy use \& its immediate complications among vaginal deliveries in 18 tertiary care hospitals in India," The Indian Journal of Medical Research, vol. 143, no. 4, pp. 474480, 2016.

[14] A. M. Friedman, C. V. Ananth, E. Prendergast, M. E. D'Alton, and J. D. Wright, "Variation in and factors associated with use of episiotomy," Journal of the American Medical Association, vol. 313, no. 2, pp. 197-199, 2015.

[15] W. Marai, "A two years retrospective review of episiotomy at Jimma teaching hospital, southwestern Ethiopia," Ethiopian Medical Journal, vol. 40, no. 2, pp. 141-148, 2002.

[16] K. Kiros and Z. Lakew, "Magnitude of episiotomy in a teaching hospital in Addis Ababa, Ethiopia," Ethiopian Medical Journal, vol. 44, no. 3, pp. 205-209, 2006.

[17] M. G. Kumera, B. W. Ademe, and G. M. Akessa, Assessment of Episiotomy Practice in Mizan Aman General Hospital, vol. 20, Assessment, Ethiopia, 2015. 
[18] J. Liljestrand, Episiotomy for vaginal birth: RHL commentary. The WHO Reproductive Health Library, World Health Organization, Geneva, 2003.

[19] Ethiopian Public Health Institute, Federal Ministry of Health, \& Averting Maternal Death and Disability, Ethiopian emergency obstetric and newborn care (EmONC) assessment 2016, Addis Ababa, Ethiopia, 2017.

[20] Y. Yemaneh, E. Sahile, A. Alehegn et al., "Assessment of the proportion and associated factors of episiotomy at public health institutions of Axum town, Tigray region, North Ethiopia, 2016," Critical Care Obstetrics and Gynecology, vol. 3, no. 4, p. 11, 2017.

[21] M. Alperin, M. A. Krohn, and K. Parviainen, "Episiotomy and increase in the risk of obstetric laceration in a subsequent vaginal delivery," Obstetrics \& Gynecology, vol. 111, no. 6, pp. 1274-1278, 2008.

[22] C. C. M. de Carvalho, A. S. R. Souza, and O. B. M. Filho, "Prevalence and factors associated with practice of episiotomy at a maternity school in Recife, Pernambuco, Brazil," Revista da Associacao Medica Brasileira, vol. 56, no. 3, pp. 333-339, 2010.

[23] B. Chigbu, S. Onwere, C. Aluka, C. Kamanu, and E. Adibe, "Factors influencing the use of episiotomy during vaginal delivery in south eastern Nigeria," East African Medical Journal, vol. 85, no. 5, pp. 240-243, 2008.

[24] R. Escuriet, M. J. Pueyo, M. Perez-Botella et al., "Cross-sectional study comparing public and private hospitals in Catalonia: is the practice of routine episiotomy changing?" $B M C$ Health Services Research, vol. 15, no. 1, p. 95, 2015.

[25] E. Izuka, C. Dim, C. Chigbu, and C. Obiora-Izuka, "Prevalence and predictors of episiotomy among women at first birth in Enugu, South-East Nigeria," Annals of Medical and Health Sciences Research, vol. 4, no. 6, pp. 928-932, 2014.

[26] S. Khani, K. Zare, and S. Ramezannezhad, "The frequency of episiotomy and its related factors," Iran Journal of Nursing (2008-5923), vol. 24, no. 74, 2012.

[27] A. T. Trinh, A. Khambalia, A. Ampt, J. M. Morris, and C. L. Roberts, "Episiotomy rate in Vietnamese-born women in Australia: support for a change in obstetric practice in Viet Nam," Bulletin of the World Health Organization, vol. 91, no. 5, pp. 350-356, 2013.

[28] F. Pebolo, A. Judith, and K. Kabonge Dan, "Prevalence and factors associated with episiotomy practice among primiparous women in Mulago national referral hospital Uganda," International Journal of Pregnancy \& Child Birth, vol. 5, no. 5, pp. 197-201, 2019.

[29] A. N. Ocheke, E. Samuels, I. E. Ocheke et al., "An audit of perineal trauma and vertical transmisson of HIV," African Journal of Reproductive Health, vol. 21, no. 4, pp. 67-72, 2017.

[30] E. C. Inyang-Etoh and A. J. Umoiyoho, "The practice of episiotomy in a university teaching hospital in Nigeria: how satisfactory?," International Journal of Medicine and Biomedical Research, vol. 1, no. 1, pp. 68-72, 2012.

[31] M. Rasouli, A. Keramat, A. Khosravi, and Z. Mohabatpour, "Prevalence and factors associated with episiotomy in Shahroud City, northeast of Iran," International Journal of Women's Health and Reproduction Sciences, vol. 4, no. 3, pp. 125-129, 2016.

[32] I. Garba, M. Ozegya, I. Abubakar, and R. Ayyuba, "Episiotomy at Aminu Kano teaching hospital, Kano, Nigeria: a 3-year review," Archives of International Surgery, vol. 6, no. 1, pp. 17-21, 2016.
[33] A. Joshi and R. Acharya, "Perineal outcome after restrictive use of episiotomy in primi-gravidas," JNMA; Journal of the Nepal Medical Association, vol. 48, no. 176, pp. 269-272, 2009.

[34] F. B. Belihu, R. Small, and M. A. Davey, "Episiotomy and severe perineal trauma among eastern African immigrant women giving birth in public maternity care: a population based study in Victoria, Australia," Women and Birth: Journal of the Australian College of Midwives, vol. 30, no. 4, pp. 282290, 2017.

[35] S. A. Worku, Y. M. Mitku, and S. A. Getahun, "Episiotomy practice and its associated factor among women who gave birth at public health institutions of Akaki Kality in Addis Ababa, Ethiopia," Clinics Mother Child Health, vol. 16, p. 318, 2019.

[36] L. A. Smith, N. Price, V. Simonite, and E. E. Burns, "Incidence of and risk factors for perineal trauma: a prospective observational study," BMC Pregnancy and Childbirth, vol. 13, no. 1, p. 59, 2013.

[37] C. Schantz, K. L. Sim, E. M. Ly, H. Barennes, S. Sudaroth, and S. Goyet, "Reasons for routine episiotomy: a mixed-methods study in a large maternity hospital in Phnom Penh, Cambodia," Reproductive Health Matters, vol. 23, no. 45, pp. 68-77, 2015.

[38] W. C. Hsieh, C. C. Liang, D. Wu, S. D. Chang, H. Y. Chueh, and A. S. Chao, "Prevalence and contributing factors of severe perineal damage following episiotomy-assisted vaginal delivery," Taiwanese Journal of Obstetrics \& Gynecology, vol. 53, no. 4, pp. 481-485, 2014.

[39] L. Lowenstein, L. Haddad, J. Itskovitz-Eldor, E. Sabo, and P. Jakobi, "Episiotomy as a risk factor for early perineal trauma," Harefuah, vol. 144, no. 6, pp. 389-93, 456, 2005, 456.

[40] G. Hudelist, J. Gelle'n, C. Singer et al., "Factors predicting severe perineal trauma during childbirth: role of forceps delivery routinely combined with mediolateral episiotomy," American Journal of Obstetrics and Gynecology, vol. 192, no. 3, pp. 875-881, 2005.

[41] C. Ballesteros-Meseguer, C. Carrillo-García, M. Meseguer-dePedro, M. Canteras-Jordana, and M. E. Martínez-Roche, "Episiotomy and its relationship to various clinical variables that influence its performance," Revista Latino-Americana de Enfermagem, vol. 24, article e2793, 2016.

[42] R. Sooklim, J. Thinkhamrop, P. Lumbiganon et al., "The outcomes of midline versus medio-lateral episiotomy," Reproductive Health, vol. 4, no. 1, p. 10, 2007.

[43] L. M. Christianson, V. E. Bovbjerg, E. C. McDavitt, and K. L. Hullfish, "Risk factors for perineal injury during delivery," American Journal of Obstetrics and Gynecology, vol. 189, no. 1, pp. 255-260, 2003.

[44] A. Shmueli, R. Gabbay Benziv, L. Hiersch et al., "Episiotomy risk factors and outcomes," The Journal of Maternal-Fetal \& Neonatal Medicine, vol. 30, no. 3, pp. 251-256, 2016.

[45] U. Magriples, T. S. Kershaw, S. S. Rising, C. Westdahl, and J. R. Ickovics, "The effects of obesity and weight gain in young women on obstetric outcomes," American Journal of Perinatology, vol. 26, no. 5, pp. 365-371, 2009.

[46] K. Gallagher, L. Migliaccio, R. G. Rogers, L. Leeman, E. Hervey, and C. Qualls, "Impact of nulliparous women's body mass index or excessive weight gain in pregnancy on genital tract trauma at birth," Journal of Midwifery \& Women's Health, vol. 59, no. 1, pp. 54-59, 2014. 
[47] H. J. Landy, S. K. Laughon, J. L. Bailit et al., "Characteristics associated with severe perineal and cervical lacerations during vaginal delivery," Obstetrics and Gynecology, vol. 117, no. 3, pp. 627-635, 2011.

[48] M. Blomberg, "Maternal body mass index and risk of obstetric anal sphincter injury," BioMed Research International, vol. 2014, Article ID 395803, 8 pages, 2014.

[49] C. M. Durnea, A. E. Jaffery, N. Gauthaman, and S. K. Doumouchtsis, "Effect of body mass index on the incidence of perineal trauma," International Journal of Gynecology \& Obstetrics, vol. 141, no. 2, pp. 166-170, 2018. 